\title{
Cognitive predictors of violent incidents in forensic psychiatric inpatients
}

Citation for published version (APA):

Brugman, S., Lobbestael, J., von Borries, K., Bulten, B. H., Cima, M., Schuhmann, T., Dambacher, F., Sack, A. T., \& Arntz, A. (2016). Cognitive predictors of violent incidents in forensic psychiatric inpatients. Psychiatry Research, 237, 229-237. https://doi.org/10.1016/j.psychres.2016.01.035

Document status and date:

Published: 30/03/2016

DOI:

10.1016/j.psychres.2016.01.035

Document Version:

Publisher's PDF, also known as Version of record

Document license:

Taverne

Please check the document version of this publication:

- A submitted manuscript is the version of the article upon submission and before peer-review. There can be important differences between the submitted version and the official published version of record.

People interested in the research are advised to contact the author for the final version of the publication, or visit the DOI to the publisher's website.

- The final author version and the galley proof are versions of the publication after peer review.

- The final published version features the final layout of the paper including the volume, issue and page numbers.

Link to publication

\footnotetext{
General rights rights.

- You may freely distribute the URL identifying the publication in the public portal. please follow below link for the End User Agreement:

www.umlib.nl/taverne-license

Take down policy

If you believe that this document breaches copyright please contact us at:

repository@maastrichtuniversity.nl

providing details and we will investigate your claim.
}

Copyright and moral rights for the publications made accessible in the public portal are retained by the authors and/or other copyright owners and it is a condition of accessing publications that users recognise and abide by the legal requirements associated with these

- Users may download and print one copy of any publication from the public portal for the purpose of private study or research.

- You may not further distribute the material or use it for any profit-making activity or commercial gain

If the publication is distributed under the terms of Article $25 \mathrm{fa}$ of the Dutch Copyright Act, indicated by the "Taverne" license above, 


\title{
Cognitive predictors of violent incidents in forensic psychiatric inpatients
}

\author{
Suzanne Brugman ${ }^{\mathrm{a}, *}$, Jill Lobbestael ${ }^{\mathrm{a}}$, A. Katinka L. von Borries ${ }^{\mathrm{b}}$, Berend (Erik) H. Bulten ${ }^{\mathrm{b}}$, \\ Maaike Cima ${ }^{\mathrm{c}, \mathrm{d}}$, Teresa Schuhmann ${ }^{\mathrm{e}, \mathrm{f}}$, Franziska Dambacher ${ }^{\mathrm{e}, \mathrm{f}}$, Alexander T. Sack ${ }^{\mathrm{e}, \mathrm{f}}$, \\ Arnoud Arntz ${ }^{g}$ \\ a Department of Clinical Psychological Science, Faculty of Psychology and Neuroscience, Maastricht University, The Netherlands \\ ${ }^{\mathrm{b}}$ Pompekliniek Nijmegen, The Netherlands \\ ${ }^{\mathrm{c}}$ Department of Research, Forensic Psychiatric Centre de Rooyse Wissel, The Netherlands \\ d Department of Developmental Psychology, Radboud University, Nijmegen, The Netherlands \\ e Department of Cognitive Neuroscience, Faculty of Psychology and Neuroscience, Maastricht University, The Netherlands \\ ${ }^{\mathrm{f}}$ Maastricht Brain Imaging Center, The Netherlands \\ ${ }^{\mathrm{g}}$ Department of Clinical Psychology, Faculty of Social and Behavioural Sciences, University of Amsterdam, The Netherlands
}

\section{A R T I C L E I N F O}

\section{Article history:}

Received 29 April 2015

Received in revised form

23 October 2015

Accepted 15 January 2016

Available online 16 January 2016

\section{Keywords:}

Aggressive behavior

Cognitive bias

Forensic patients

Dynamic factors

Violent incidents

\begin{abstract}
A B S T R A C T
This study tested the predictive value of attentional bias, emotion recognition, automatic associations, and response inhibition, in the assessment of in-clinic violent incidents. Sixty-nine male forensic patients participated and completed an Emotional Stroop to measure attentional bias for threat and aggression, a Single Target - Implicit Association Task to assess automatic associations, a Graded Emotional Recognition Task to measure emotion recognition, and an Affective Go/NoGo to measure response inhibition. Violent incidents were derived from patient files and scored on severity level. The predictive value of level of psychopathy was tested with the Psychopathy Checklist - Revised (PCL-R). Generalized linear mixed model analyses showed that increased attention towards threat and aggression, difficulty recognizing sad faces and factor 2 of the PCL-R predicted the sum of violent incidents. Specifically, verbal aggression was predicted by increased attention towards threat and aggression, difficulty to recognize sad and happy faces, and PCL-R factor 2; physical aggression by decreased response inhibition, higher PCL-R factor 2 and lower PCL-R factor 1 scores; and aggression against property by difficulty recognizing angry faces. Findings indicate that cognitive tasks could be valuable in predicting aggression, thereby extending current knowledge on dynamic factors predicting aggressive behavior in forensic patients.

(c) 2016 Elsevier Ireland Ltd. All rights reserved.
\end{abstract}

\section{Introduction}

Aggressive behavior is one of the main problems that staff members in forensic psychiatric settings cope with (Nijman and Geurkink, 2004; Kobes et al., 2012; Ros et al., 2013; Wilson et al., 2013). Minimizing incidents in forensic settings is therefore essential and being able to predict incidents might facilitate this. Various risk taxation instruments are used to predict future violent behavior of patients. Recently, an increase exists in studies on risk assessment tools that include dynamic factors (e.g. Wilson et al., 2013; Chan and Chow, 2014), as these factors are changeable and targetable. Cognitive processes can be seen as dynamic and have theoretically been linked to aggressive behavior (Crick and

\footnotetext{
* Correspondence to: Department of Clinical Psychological Science (CPS), Faculty of Psychology and Neuroscience (FPN), Maastricht University, Universiteitssingel 40, P.O. Box 616, 6200 MD Maastricht, The Netherlands.

E-mail address: suzanne.brugman@maastrichtuniversity.nl (S. Brugman).
}

Dodge, 1994), indicating that research on the predictive value of these processes could be promising. Although the correlation between cognitive factors and aggressive behavior in different populations has been studied numerously (e.g. Brugman et al., 2015; Chan et al., 2010; Dambacher et al., 2014; Domes et al., 2013; Eckhardt et al., 2012; Iria et al., 2012; Lobbestael et al., 2009; Pham and Philippot, 2010; Schönenberg et al., 2014; Smith and Waterman, 2003; Snowden et al., 2004; Wilson et al., 2011) little is known on the predictive value of these cognitive factors in the assessment of future aggressive behavior of forensic psychiatric patients (i.e. criminal offenders with a psychiatric disorder). The aim of this study is to examine whether cognitive factors predict in-clinic aggressive behavior of forensic psychiatric patients.

Recent literature on implicit cognitive factors related to violent behavior has addressed four dimensions. The first dimension is that of attention. An attentional bias towards negative stimuli has been observed in male batterers (Chan et al., 2010). Furthermore, Brugman et al. (2015) showed that a heightened attentional bias 
towards aggressive stimuli predicted more reactive aggressive behavior in a male sample of the general population. Although both studies did not assess forensic psychiatric patients, the results indicate that attentional interference of negative and aggressive stimuli is associated with violent behavior in men. The studies of Bass and Nussbaum (2010), Domes et al. (2013), and Smith and Waterman (2003) on forensic psychiatric patients found a similar relation between attentional interference and aggression. Deficits in attentional performance have been associated with anger-related aggression in forensic psychiatric patients (Bass and Nussbaum, 2010). Domes et al. (2013) showed that forensic psychiatric patients (i.e. criminal offenders with antisocial personality disorder) showed a stronger attentional bias towards negative and violence-related stimuli than offenders without this disorder and non-criminal controls. Finally, violent offenders showed an attentional bias towards aggressive words as opposed to non-violent offenders and undergraduates (Smith and Waterman, 2003).

The second dimension is that of automatic associations. Automatic associations between concepts like'violent' and evaluations like 'good' have proven to be related to aggressive behavior in different populations. In non-forensic populations it was found that participants enrolled in an intimate partner violence treatment program had a more positive implicit association with violence than controls (Eckhardt et al., 2012). The results of Richetin et al. (2010) indicated that measuring an automatic self- aggression association after provocation predicted aggressive behavior in undergraduates. The study of Banse et al. (2015) indicated that the IAT with aggressive stimuli had predictive value for aggressive behavior in the laboratory as well as more natural settings (i.e. ice hockey). Moreover, in forensic psychiatric samples a relation between automatic associations and aggression was found. Psychopathic murderers showed an abnormal implicit attitude towards violence compared to non-psychopathic murderers and non-murderers (Snowden et al., 2004). Also, after an anger induction an automatic self-aggression association was shown in antisocial patients (Lobbestael et al., 2009). Furthermore, Zwets et al. (2015) showed that a more positive association with violence was associated with the antisocial facet of psychopathy and self-reported hostility, while a more negative association with violence was related to more socially adapted behavior. Following these studies, automatic associations with aggression may be predictive of violent incidents in forensic psychiatric inpatients.

The third dimension is emotion recognition. A variety of studies exists on facial processing in psychopathic offenders (e.g. Wilson et al., 2011) indicating that psychopaths are impaired in recognizing fearful and sad expression. Non-psychopathic criminals showed difficulty in recognizing emotional faces in comparison to controls (Pham and Philippot, 2010). Antisocial violent offenders interpreted ambiguous facial cues as more hostile than healthy controls (Schönenberg and Jusyte, 2014), showing that antisocial offenders not only have problems recognizing emotional faces but also have an interpretation bias when viewing faces.

The fourth dimension is response inhibition, or the ability to refrain from selecting social inappropriate responses (such as aggressive behavior). Dambacher et al. (2014) showed that the anterior insula cortex is involved in behavioral inhibition and aggressive behavior in response to a provocation, indicating similar brain structures for poor response inhibition and reactive aggression. Decreased response inhibition in emotional contexts has also been shown to be associated with aggressive behavior. Iria et al. (2012) showed that psychopathic and non-psychopathic criminals have a tendency of over-responsiveness (i.e. more false alarms) to angry and fearful faces in comparison with non-criminal participants with low psychopathy scores.

Although the above biases and distortions in attention, automatic association, emotion recognition, and response inhibition have been linked to aggressive behavior in different populations, their value for predicting aggressive behavior in forensic psychiatric patients remains unknown. This explorative study therefore examined whether an attentional bias for threatening and aggressive words; distortions in recognizing and interpreting expressive faces; a positive attitude towards violence; and response inhibition in context of affective stimuli were predictive for the number and severity of violent incidents displayed by forensic psychiatric patients. To control for the predictive value of static factors, we included the level of psychopathy, a stable characteristic that has been shown to predict violent behavior and recidivism (e.g. Hare et al., 2000). Violent incidents over a one-year period were assessed, enabling the examination of the predictive value of the cognitive measures of long-term in-clinic aggressive behavior in a forensic sample. To our best knowledge, this is the first study to test the predictive value of different cognitive factors in a longitudinal way for violent behavior in a forensic patient sample.

\section{Methods}

\subsection{Participants}

Sixty-nine Dutch male forensic psychiatric inpatients of two forensic psychiatric hospitals or so-called 'TBS-clinics ${ }^{1}$ (i.e. Pompekliniek, Nijmegen, and FPC Oldenkotte, Rekken, the Netherlands) participated in the study. Descriptive statistics for age, educational level (Verhage, 1964), mean IQ, DSM axis I and II diagnoses (established by means of extensive observation by mental health professionals), type of index crime, mean age at first reconviction, and amount of participants with a PCL-r score of 26 or higher (i.e. the European cut-off score of psychopathy; Grann et al., 1999) can be found in Table 1. Child molesters were excluded from this study because research indicates a very distinct set of cognitive distortions in this group (e.g. automatic association between children and sexual words, self-serving interpretations of victim experience; Gannon and Polaschek, 2006). Also, violent behavior is not often used in these patients when committing offenses (Rebocho and Gonçalves, 2012), indicating that aggressive behavior is not the main issue for these patients. Patients with current/history of psychosis or dissociative disorder were excluded from this study, as violent behavior in these patients is linked to their psychotic symptoms (e.g. threat/control-override symptoms such as 'Others tried to poison me'; Nederlof, et al., 2011), whereas we were interested in the influence of aggression-related cognitions.

\subsection{Materials}

\subsubsection{Emotional Stroop}

For attentional interference, two versions of the Emotional Stroop were used: one with neutral and general threat-related words, the other with neutral and aggression-related words ${ }^{2}$. Both included a practice block of 16 trials and 2 blocks of 44 trials. In each block, 22 words were neutral and 22 words were either threat-related (e.g. "illness") or aggression-related (e.g. "attack"). Stimuli were used once and randomized per block. The words

${ }^{1}$ TBS or 'terbeschikkingstelling' can be translated as "disposal to be treated on behalf of the state'. By the Dutch law, one cannot be sentenced without criminal liability. If a person commits a serious criminal offense that is linked with his mental disorder, he is not liable or has diminished responsibility for this crime. However, if he is a serious danger to himself or others, the Dutch court will order the person to be submitted to a secure institution through an entrustment act.

${ }^{2}$ In both Stroop-versions, words were matched on type, length and frequency based on information from the CELEX database. A 'test panel' of 15 persons rated how well the words fitted into the categories on a Likert-scale (1-5). 
Table 1

Descriptive Statistics for Demographic and Clinical Variables.

\begin{tabular}{|c|c|}
\hline Descriptives & \\
\hline Age, mean (SD) & $37.9(7.9)$ \\
\hline \multicolumn{2}{|l|}{ Educational level $^{\mathrm{a}}, N(\%)$} \\
\hline Less than six years of primary education & $2(2.9)$ \\
\hline Finished six years of primary education & $4(5.8)$ \\
\hline $\begin{array}{l}\text { Six years primary education and less than two years of low level } \\
\text { secondary education }\end{array}$ & $34(49.3)$ \\
\hline Four years of low level secondary education & $20(29.0)$ \\
\hline Four years of average level secondary education & $5(7.2)$ \\
\hline Five years of high level secondary education & $2(2.9)$ \\
\hline University degree & $1(1.4)$ \\
\hline $\mathrm{IQ}^{\mathrm{b}}$, mean $(\mathrm{SD})$ & $96.6(11.1)$ \\
\hline \multicolumn{2}{|l|}{ Axis I diagnosis, $\mathrm{N}(\%)$} \\
\hline Substance-related disorder (one substance) & $19(27.5)$ \\
\hline Substance-related disorder (multiple substances) & $34(49.3)$ \\
\hline Mood disorder & $2(2.9)$ \\
\hline Anxiety disorder/PTSS & $3(4.3)$ \\
\hline Pervasive developmental disorder & $1(1.4)$ \\
\hline Attention deficit and disruptive behavior disorder & $6(8.7)$ \\
\hline Impulse control disorder & $8(11.6)$ \\
\hline Paraphilia & $4(5.8)$ \\
\hline Missing & $1(1.4)$ \\
\hline Other (i.e. cognitive disorder NOS; pain disorder) & $2(2.8)$ \\
\hline No diagnosis on axis I & $9(13.0)$ \\
\hline Diagnosis on axis I deferred & $1(1.4)$ \\
\hline \multicolumn{2}{|l|}{ Axis II diagnosis, $N(\%)$} \\
\hline Paranoid PD & $1(1.4)$ \\
\hline Antisocial PD & $26(37.7)$ \\
\hline Narcissistic PD & $8(11.6)$ \\
\hline Borderline PD & $6(8.7)$ \\
\hline Personality disorder NAO & $33(47.8)$ \\
\hline With Cluster B features & $16(23.2)$ \\
\hline With Cluster C features & $2(2.9)$ \\
\hline With features of multiple clusters & $14(20.3)$ \\
\hline Features not specified & $1(1.4)$ \\
\hline \multicolumn{2}{|l|}{ Type of index crime } \\
\hline Violent crime ${ }^{\mathrm{c}}$ & $65(94.2)$ \\
\hline Sexual crime & $22(31.9)$ \\
\hline Property crime & $23(33.3)$ \\
\hline Mean age at first reconviction, mean (SD) & $19.7(6.4)$ \\
\hline Amount of participants with PCL-R score of $\geq 26, N(\%)$ & $31(44.9)$ \\
\hline
\end{tabular}

were presented for $200 \mathrm{~ms}$, without backward masking and with interval duration of $1300 \mathrm{~ms}$. Participants were asked to push the button corresponding to the color of the word. Reaction times on neutral, threat-related, and aggression-related stimuli were recorded and excluded from analyses when shorter than $150 \mathrm{~ms}$ or larger than $1500 \mathrm{~ms}$. Incorrect trials were also excluded. A Stroopeffect was calculated following Smith and Waterman (2003): $\mathrm{RT}_{\text {general }}$ threat $-\mathrm{RT}_{\text {neutral }}$ for the general threat-version and $\mathrm{RT}_{\text {aggression }}-\mathrm{RT}_{\text {neutral }}$ for the aggression-version.

\subsubsection{Signal Detection Task}

The Signal Detection Task measured vigilance for threatening stimuli. Following the research of Öhman et al. (2001) matrices of 9 schematic faces were presented. The participant was asked to decide whether all faces in the matrix showed the same expression or whether one was different. The task consisted of 4 blocks with 25 target-trials (i.e. one different expression) and 25 non-target trials (i.e. all faces with the same expression): block 1 : target=happy, distractors=neutral; block 2: target=angry, distractors=neutral; block 3: target $=$ neutral, distractors=angry; block 4: target $=$ neutral, distractors =happy. Matrices were presented for $180 \mathrm{~ms}$ and backward masking ( $200 \mathrm{~ms}$, stripe pattern over the schematic faces) was used. Responses faster than $150 \mathrm{~ms}$ and longer than $1500 \mathrm{~ms}$ were eliminated. Following the signal detection theory of MacMillan and Creelman (1991), four sensitivity indexes $\left(d^{\prime}\right)$ were used to examine vigilance for emotional faces among neutral faces and difficulty to disengage from emotional faces when detecting a neutral face: 1) $d^{\prime}$ for a happy face among neutral faces, 2) $d^{\prime}$ for an angry face among neutral faces, 3 ) $d^{\prime}$ for a neutral face among happy faces and, 4) $d^{\prime}$ for a neutral face among angry faces. To examine vigilance and difficulty to disengage for angry faces specifically, the following calculations were done: 1) $d^{\prime}$ for angry faces among neutral ones minus $d^{\prime}$ for happy faces among neutral ones, 2) $d^{\prime}$ for a neutral face among angry faces minus $d^{\prime}$ for a neutral face among happy faces. A higher score reflected higher vigilance or more difficulty to disengage from angry than happy faces.

\subsubsection{Graded Emotional Recognition Task (GERT)}

With the GERT, we measured the ability to recognize and interpret emotional faces of different intensity levels. Participants were shown male and female faces (Ekman and Friesen, 1976) displaying anger, disgust, anxiety, happiness, sadness, surprise or a neutral expression. The emotions were expressed on $40 \%, 70 \%$ or $100 \%$ intensity level. The task existed of 252 trials and each emotion was presented 36 times in random order (12 trials per emotion intensity). Difficulty to recognize emotional faces at $100 \%$, $70 \%$, and $40 \%$ intensity was measured by the number of incorrect responses on these trials.

\subsubsection{Implicit Association Task (IAT)}

To assess whether a positive automatic association with violence predicted aggressive behavior, an IAT was used. The task consisted of 7 blocks: 1) participants categorized positive and negative words ${ }^{3}$ according to labels 'positive' and 'negative' by using the left and right cursor, 2) pictures ${ }^{4}$ of violent or nonviolent situations were categorized under 'violent' and 'nonviolent', 3) positive words and violent pictures were categorized using the right cursor and negative words and nonviolent pictures with the left cursor, 4) test block with same instructions as third block, 5) violent pictures were categorized to the left and nonviolent pictures to the right, 6) nonviolent pictures were categorized together with positive words and violent pictures were categorized together with negative words, 7) test block with same instructions as sixth block. Reaction times during the test blocks were recorded. The IAT-effect was calculated (reaction times on block 7 reaction times on block 4) following the procedure of Snowden et al. (2004). A higher IAT-effect reflected faster reaction times on the incompatible block in contrast to the compatible block, indicating a more positive attitude towards violence.

\subsubsection{Affective Go/NoGo}

With the Affective Go/NoGo task, response inhibition on emotional stimuli was measured. Participants pushed the spacebar in reaction to some pictures (i.e. go-trial), while not reacting to other pictures (i.e. no-go trial). The task consisted of 6 blocks with 32

\footnotetext{
${ }^{3}$ Words were selected from the CELEX-database.

${ }^{4}$ Pictures were selected from IAPS (International Affective Picture System; Lang et al., 1997) and the internet, which were matched on complexity and color scheme.
} 
trials (16 go-trials and 16 no-go trials), differing in instructions: 1 ) $\mathrm{Go}=$ positive pictures, $\mathrm{No} / \mathrm{Go}=$ negative pictures, 2) $\mathrm{Go}=$ negative pictures, No/Go=positive pictures, 3 ) $\mathrm{Go}=$ positive pictures, No/ $\mathrm{Go}=$ neutral pictures, 4) $\mathrm{Go}=$ neutral pictures, No/Go=positive pictures, 5) $\mathrm{Go}=$ negative pictures, $\mathrm{No} / \mathrm{Go}=$ neutral pictures, and 6) $\mathrm{Go}=$ neutral pictures, $\mathrm{No} / \mathrm{Go}=$ negative pictures. Pictures were derived from the International Affective Picture System (IAPS; Lang, et al., 1997). Information about which pictures were used, can be found in the Supplementary material online ${ }^{5}$. Reaction times and response accuracy were recorded. Following Nosek and Banaji (2001), $d^{\prime}$ indexes were calculated. $D^{\prime}$ indexes indicated sensitivity to discriminate target positive pictures from negative or neutral pictures, to discriminate negative from positive or neutral pictures, and to discriminate neutral pictures from positive and negative pictures. The higher the $d^{\prime}$ score, the higher the sensitivity to discriminate the target pictures from the distractor pictures.

\subsubsection{Psychopathy-Checklist revised (PCL-R)}

To indicate the level of psychopathic traits, the PCL-R (Hare, 2003) was used (ICC between 0.85 and 0.95; Hare, 2003), which is shown to be a good indicator of violent recidivism (e.g. Hare et al., 2000). PCL-R scores were derived from the patient files. PCL-R scores were missing for 3 participants. For one additional patient, only the PCL-R total score was available. The PCL-R scores from the patient files were obtained by certified clinicians, using interviews and patient file information to reach one consensus score. Interrater reliability and internal consistency of the Dutch version of the PCL-R were found to be high (ICC $=0.88$ and $\alpha=0.87$, respectively; Hildebrand, et al., 2002).

\subsubsection{Aggressive incidents}

All aggressive incidents were selected from the MITS (monitoring information system of TBS) taking place during one year after administering the cognitive task. Each incident was scored by the first author on severity using the Modified Overt Aggression Scale (MOAS; Sorgi et al., 1991), which exists of four scales: verbal aggression, aggression against property, auto-aggression, and physical aggression. In this study auto-aggression incidents were not scored. Severity on each scale ranges from 0 (not present, e.g. "No verbal aggression") to 4 (severely present, e.g. "Threatens violence toward others or self repeatedly or deliberately “). Multiple severity scores on the same scale could be scored and summed to a total severity score. Also, multiple types of aggression could be present within one incident. One of the co-authors (F.D.) randomly scored 50 incidents, which resulted in an inter-rater reliability of 0.97 on verbal aggression, 1.00 on aggression against property, and 0.97 on physical aggression. The number and severity (expressed as average per incident in case of multiple incidents) of incidents per month were used as outcome measures for the patients.

\subsection{Procedure}

Clinicians were asked for permission to contact patients meeting the inclusion criteria. Next, selected patients were asked for participation and provided with information about the study. If the patient agreed on participating, meetings were planned to conduct the experiment (three sessions of $2 \mathrm{~h}$ maximum). Debriefing was not necessary, since the goal of the study was explained beforehand. This study was approved by the 'Medisch Ethische Toetsingscommissie' of CMO Arnhem-Nijmegen (METC; Medical Ethical Committee).

\footnotetext{
${ }^{5}$ A 'test panel' of 27 persons rated the pictures along a Likert scale on each used category, to be able to select the pictures that represented the category best.
}

\subsection{Regression analyses}

Generalized linear mixed model analyses were used to predict the number of aggressive incidents per month within one year after each cognitive task. Each cognitive task was tested in a separate regression analysis, as the $N$ varied per cognitive task. PCL-R factor scores were included in the analyses to examine the predictive value of the cognitive measurements next to the static factor of psychopathy. As the number of aggressive incidents was negatively skewed and to eliminate the influence of overdispersion, negative binomial regression with a log link was chosen over linear and Poisson regression. Compound symmetry was chosen for the repeated part, as this led to the best fitting models. An exception was made for the Affective Go/NoGo task, as the full model did not converge with negative binomial mixed regression with a log link. Data on this task was analyzed with a Poisson regression and compound symmetry covariance structure. Backwards stepwise regression was used to eliminate variables that did not predict violent incidents $\left(\alpha_{\text {criterion }}=0.10\right)$. Predictors with $p<0.05$ were interpreted as significant. Only the final fitting model will be reported. As time, both as factor and as linear covariate, was not significant in most models in the fixed part, it was deleted, except for the Affective Go/NoGo task. Adding random intercept and both random intercept and time as random slope to the model led to estimation failure. To examine whether the cognitive measures predicted the severity of violent incidents, generalized linear mixed model analysis was used in a similar manner. As severity of violent incidents was negatively skewed, gamma regressions were used to analyze the data. Compound symmetry resulted in the best fitting models. Time was a significant predictor in the fixed part only for the Affective Go/NoGo and therefore not included in the other models, and adding a random intercept and time as random slope caused estimation failure, so these were not included in the model.

\section{Results}

\subsection{Descriptives}

Patients had a mean PCL-R score of $23.97(\mathrm{SD}=7.92$, range $=5-$ $38)$, a mean factor 1 score of $9.9(\mathrm{SD}=3.85$, range $=1-16)$, and a mean factor 2 score of 11.08 ( $S D=3.75$, range $=2-17)$. Descriptives of number of incidents and severity of aggressive behavior can be found in Table 2.

\subsection{Predicting the number (Table 3) and severity (Table 4) of violent incidents}

\subsubsection{Emotional stroop}

For both versions of the task a higher attentional interference for threat-related or aggressive stimuli and a higher PCL-R factor 2 score predicted more aggressive incidents. For the aggression version a higher PCL-R factor 1 score predicted less aggressive incidents. For both versions of the task, a stronger attentional bias for threat or aggression and a higher PCL-R 2 score predicted higher severity of verbal aggression. Also for both models, a higher PCL-R factor 1 predicted less severity of physical aggression, whereas a higher PCL-R factor 2 score predicted higher severity of physical aggression.

\subsubsection{Signal Detection Task}

No significant effects were found for this task or the PCL-R factors. A higher PCL-R factor 2 predicted higher severity of verbal aggressive incidents as well as physical aggression. 
Table 2

Descriptives of Number and Severity of Violent Incidents for each Cognitive Task.

\begin{tabular}{|c|c|c|c|c|c|}
\hline & $\begin{array}{l}\text { Number of } \\
\text { participants }\end{array}$ & $\begin{array}{l}\text { Number of violent incidents } \\
\text { within one year after task }\end{array}$ & $\begin{array}{l}\text { Severity of verbal } \\
\text { aggression }\end{array}$ & $\begin{array}{l}\text { Severity of aggression } \\
\text { against property }\end{array}$ & $\begin{array}{l}\text { Severity of physical } \\
\text { aggression }\end{array}$ \\
\hline $\begin{array}{l}\text { Emotional Stroop General } \\
\text { Threat }\end{array}$ & $N=63$ & $\begin{array}{l}\Sigma=89 \\
M=1.41 \\
\mathrm{SD}=2.57 \\
\text { range }=0-12\end{array}$ & $\begin{array}{l}M=2.69 \\
\mathrm{SD}=4.53 \\
\text { Range }=0-22\end{array}$ & $\begin{array}{l}M=0.21 \\
\mathrm{SD}=0.71 \\
\text { Range }=0-3\end{array}$ & $\begin{array}{l}M=0.36 \\
\mathrm{SD}=0.96 \\
\text { Range }=0-5\end{array}$ \\
\hline $\begin{array}{l}\text { Emotional Stroop } \\
\text { Aggression }\end{array}$ & $N=61$ & $\begin{array}{l}\Sigma=85 \\
M=1.39 \\
\mathrm{SD}=2.60 \\
\text { range }=0-12\end{array}$ & $\begin{array}{l}M=2.63 \\
\mathrm{SD}=4.61 \\
\text { Range }=0-22\end{array}$ & $\begin{array}{l}M=0.22 \\
S D=0.72 \\
\text { Range }=0-3\end{array}$ & $\begin{array}{l}M=0.37 \\
\mathrm{SD}=0.98 \\
\text { Range }=0-5\end{array}$ \\
\hline Signal Detection Task & $N=63$ & $\begin{array}{l}\Sigma=85 \\
M=1.13 \\
\mathrm{SD}=2.23 \\
\text { Range }=0-11\end{array}$ & $\begin{array}{l}M=1.98 \\
\mathrm{SD}=3.84 \\
\text { Range }=0-16.5\end{array}$ & $\begin{array}{l}M=0.12 \\
S D=0.50 \\
\text { Range }=0-3\end{array}$ & $\begin{array}{l}M=0.32 \\
\mathrm{SD}=0.96 \\
\text { Range }=0-5\end{array}$ \\
\hline IAT & $N=52$ & $\begin{array}{l}\Sigma=62 \\
M=1.19 \\
\mathrm{SD}=2.29 \\
\text { Range }=0-11\end{array}$ & $\begin{array}{l}M=1.90 \\
S D=3.59 \\
\text { Range }=0-14.83\end{array}$ & $\begin{array}{l}M=0.11 \\
\mathrm{SD}=0.48 \\
\text { Range }=0-3\end{array}$ & $\begin{array}{l}M=0.41 \\
\mathrm{SD}=1.06 \\
\text { Range }=0-5\end{array}$ \\
\hline GERT & $N=51$ & $\begin{array}{l}\Sigma=67 \\
M=1.31 \\
\mathrm{SD}=2.55 \\
\text { Range }=0-12\end{array}$ & $\begin{array}{l}M=2.24 \\
\mathrm{SD}=4.58 \\
\text { Range }=0-22\end{array}$ & $\begin{array}{l}M=0.16 \\
S D=0.64 \\
\text { Range }=0-3\end{array}$ & $\begin{array}{l}M=0.46 \\
\mathrm{SD}=1.13 \\
\text { Range }=0-5\end{array}$ \\
\hline Affective Go/NoGo & $N=67$ & $\begin{array}{l}\Sigma=82 \\
M=1.22 \\
\mathrm{SD}=2.14 \\
\text { Range }=0-11\end{array}$ & $\begin{array}{l}M=2.22 \\
\mathrm{SD}=3.69 \\
\text { Range }=0-16.5\end{array}$ & $\begin{array}{l}M=0.17 \\
\mathrm{SD}=0.56 \\
\text { Range }=0-3\end{array}$ & $\begin{array}{l}M=0.31 \\
\mathrm{SD}=0.92 \\
\text { Range }=0-5\end{array}$ \\
\hline
\end{tabular}

\subsubsection{IAT}

No significant effects were found for this task or the PCL-R factors. A higher PCL-R factor 2 predicted higher severity of verbal as well as physical aggression.

\subsubsection{GERT}

The number of errors on anxious, angry, happy, disgusted and surprised faces did not predict violent incidents. For all the models, except the model for sad faces, the PCL-R factor 2 significantly positively predicted the number of violent incidents. For sad faces, a higher number of errors on $70 \%$ intense sad faces predicted a higher number of violent incidents, while a higher number of errors on $40 \%$ and $100 \%$ sad faces did not. More errors on sad faces with $70 \%$ intensity indicated higher severity of verbal aggression, while more errors on sad faces with $40 \%$ and $100 \%$ did not. Also, more errors on $40 \%$ happy faces predicted higher severity of verbal aggression. A higher PCL-R factor 2 predicted higher severity of verbal aggression in the models for anxious, angry, sad, disgusted, and surprised faces. A higher PCL-R factor 2 score predicted higher severity of physical aggression in all models. A higher severity of aggression against property was predicted by more errors on $40 \%$ angry faces.

\subsubsection{Affective Go/NoGo}

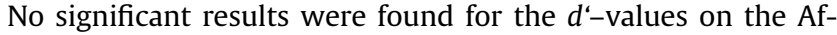
fective Go/NoGo task or the PCL-R factors. A significant result for

Table 3

Prediction of Number of Violent Incidents.

\begin{tabular}{|c|c|c|c|c|c|c|c|}
\hline Task & Variable & F-test & $\boldsymbol{B}$ & $\mathrm{SE}(\mathrm{B})$ & $\mathbf{t}$ & $\mathbf{p}$ & $\operatorname{Exp}(B)$ \\
\hline \multirow[t]{3}{*}{ Emotional Stroop General Threat } & Corrected Model & 5.543 & & & & $<0.01$ & \\
\hline & Attentional bias & 4.599 & 0.007 & 0.003 & 2.145 & $<0.05$ & 1.007 \\
\hline & PCL-R factor 2 & 7.603 & 0.175 & 0.064 & 2.757 & $<0.01$ & 1.192 \\
\hline \multirow[t]{4}{*}{ Emotional Stroop Aggression } & Corrected Model & 4.482 & & & & $<0.01$ & \\
\hline & Attentional bias & 4.301 & 0.007 & 0.003 & 2.074 & $<0.05$ & 1.007 \\
\hline & PCL-R factor 1 & 4.415 & -0.166 & 0.079 & -2.101 & $<0.05$ & 0.847 \\
\hline & PCL-R factor 2 & 11.77 & 0.303 & 0.088 & 3.431 & $<0.01$ & 1.353 \\
\hline Signal Detection Task & PCL-R factor 2 & 3.453 & 0.144 & 0.078 & 1.858 & $<0.10$ & 1.155 \\
\hline GERT anxious faces & PCL-R factor 2 & 5.840 & 0.175 & 0.073 & 2.417 & $<0.05$ & 1.191 \\
\hline GERT angry faces & PCL-R factor 2 & 5.840 & 0.175 & 0.073 & 2.417 & $<0.05$ & 1.191 \\
\hline \multirow[t]{4}{*}{ GERT sad faces } & Corrected Model & 2.153 & & & & $<0.10$ & \\
\hline & Sad $100 \%$ & 4.147 & -0.521 & 0.256 & -2.036 & $<0.05$ & 0.594 \\
\hline & Sad $70 \%$ & 6.359 & 0.646 & 0.256 & 2.522 & $<0.05$ & 1.907 \\
\hline & Sad $40 \%$ & 4.016 & -0.309 & 0.154 & -2.004 & $<0.05$ & 0.734 \\
\hline \multirow[t]{3}{*}{ GERT happy faces } & Corrected Model & 4.961 & & & & $<0.01$ & \\
\hline & Happy $40 \%$ & 3.599 & 0.178 & 0.094 & 1.897 & $<0.10$ & 1.195 \\
\hline & PCL-R factor 2 & 3.405 & 0.129 & 0.070 & 1.845 & $<0.10$ & 1.138 \\
\hline GERT disgusted faces & PCL-R factor 2 & 5.840 & 0.175 & 0.073 & 2.417 & $<0.05$ & 1.191 \\
\hline GERT surprised faces & PCL-R factor 2 & 5.840 & 0.175 & 0.073 & 2.417 & $<0.05$ & 1.191 \\
\hline \multirow[t]{3}{*}{ Affective Go/NoGo } & Corrected Model & 3.435 & & & & $<0.05$ & \\
\hline & Time & 4.031 & -0.072 & 0.036 & -2.008 & $<0.05$ & 0.931 \\
\hline & PCL-R factor 2 & 2.839 & 0.104 & 0.062 & 1.685 & $<0.10$ & 1.109 \\
\hline
\end{tabular}

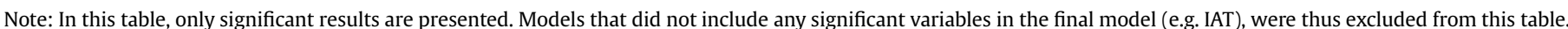
$P$-values of $<0.10$ were also displayed as the $\alpha$-criterion to eliminate variables was 0.10 . These effects are, however, not interpreted in the paper as significant results. 
Table 4

Prediction of Severity of Verbal Aggression, Physical Aggression, and Aggression against Property.

\begin{tabular}{|c|c|c|c|c|c|c|}
\hline Task & Variable & F-test & B & SE(B) & $\mathbf{t}$ & Sig. (p) \\
\hline & Verbal Aggression & & & & & \\
\hline \multirow[t]{5}{*}{ Emotional Stroop Threat } & Corrected Model & 7.290 & & & & $<0.001$ \\
\hline & Attentional bias & 11.436 & 0.002 & 0.001 & 3.382 & $<0.01$ \\
\hline & PCL-R factor 1 & 3.509 & -0.022 & 0.012 & -1.873 & $<0.10$ \\
\hline & PCL-R factor 2 & 12.980 & 0.043 & 0.012 & 3.603 & $<0.01$ \\
\hline & Physical Aggression & & & & & \\
\hline \multirow[t]{4}{*}{ Emotional Stroop Threat } & Corrected Model & 6.491 & & & & $<0.01$ \\
\hline & PCL-R factor 1 & 3.970 & -0.006 & 0.003 & -1.993 & $<0.05$ \\
\hline & PCL-R factor 2 & 12.599 & 0.012 & 0.003 & 3.549 & $<0.001$ \\
\hline & Verbal Aggression & & & & & \\
\hline \multirow[t]{5}{*}{ Emotional Stroop Aggression } & Corrected Model & 4.582 & & & & $<0.01$ \\
\hline & Attentional bias & 4.326 & 0.001 & 0.001 & 2.080 & $<0.05$ \\
\hline & PCL-R factor 1 & 3.211 & -0.023 & 0.013 & -1.792 & $<0.10$ \\
\hline & PCL-R factor 2 & 10.594 & 0.042 & 0.013 & 3.255 & $<0.01$ \\
\hline & Physical Aggression & & & & & \\
\hline \multirow[t]{4}{*}{ Emotional Stroop Aggression } & Corrected Model & 6.553 & & & & $<0.01$ \\
\hline & PCL-R factor 1 & 3.910 & -0.006 & 0.003 & -1.977 & $<0.05$ \\
\hline & PCL-R factor 2 & 12.734 & 0.012 & 0.003 & 3.568 & $<0.001$ \\
\hline & Verbal Aggression & & & & & \\
\hline \multirow[t]{2}{*}{ Signal Detection Task } & PCL-R factor 2 & 4.961 & 0.021 & 0.009 & 2.227 & $<0.05$ \\
\hline & Physical Aggression & & & & & \\
\hline \multirow[t]{4}{*}{ Signal Detection Task } & Corrected Model & 5.411 & & & & $<0.01$ \\
\hline & PCL-R factor 1 & 3.325 & -0.006 & 0.004 & -1.823 & $<0.10$ \\
\hline & PCL-R factor 2 & 10.478 & 0.011 & 0.004 & 3.237 & $=0.001$ \\
\hline & Verbal Aggression & & & & & \\
\hline \multirow[t]{4}{*}{ IAT } & Corrected Model & 3.173 & & & & $<0.05$ \\
\hline & PCL-R factor 1 & 3.326 & -0.022 & 0.012 & -1.842 & $<0.10$ \\
\hline & PCL-R factor 2 & 6.290 & 0.031 & 0.012 & 2.508 & $<.05$ \\
\hline & Physical Aggression & & & & & \\
\hline \multirow[t]{4}{*}{ IAT } & Corrected Model & 4.249 & & & & $<0.05$ \\
\hline & PCL-R factor 1 & 3.279 & -0.007 & 0.004 & -1.811 & $<0.10$ \\
\hline & PCL-R factor 2 & 8.481 & 0.012 & 0.004 & 2.912 & $<0.01$ \\
\hline & Verbal Aggression & & & & & \\
\hline GERT anxiety & PCL-R factor 2 & 5.734 & 0.027 & 0.011 & 2.395 & $<0.05$ \\
\hline GERT anger & PCL-R factor 2 & 5.734 & 0.027 & 0.011 & 2.395 & $<0.05$ \\
\hline \multirow[t]{5}{*}{ GERT sadness } & Corrected model & 4.857 & & & & $<0.01$ \\
\hline & Sad $100 \%$ & 5.477 & -0.061 & 0.026 & -2.340 & $<0.05$ \\
\hline & Sad $70 \%$ & 11.254 & 0.075 & 0.022 & 3.355 & $<0.01$ \\
\hline & Sad $40 \%$ & 6.159 & -0.042 & 0.017 & -2.482 & $<0.05$ \\
\hline & PCL-R factor 2 & 5.170 & 0.022 & 0.010 & 2.274 & $<0.05$ \\
\hline \multirow[t]{3}{*}{ GERT happy } & Corrected Model & 5.448 & & & & $<0.01$ \\
\hline & Happy $40 \%$ & 4.696 & 0.032 & 0.015 & 2.167 & $<0.05$ \\
\hline & PCL-R factor 2 & 3.639 & 0.021 & 0.011 & 1.907 & $<0.10$ \\
\hline GERT surprised & PCL-R factor 2 & 5.734 & 0.027 & 0.011 & 2.395 & $<0.05$ \\
\hline \multirow[t]{2}{*}{ GERT disgusted } & PCL-R factor 2 & 5.734 & 0.027 & 0.011 & 2.395 & $<0.05$ \\
\hline & Physical Aggression & & & & & \\
\hline GERT anxious & PCL-R factor 2 & 11.469 & 0.011 & 0.003 & 3.387 & $<0.01$ \\
\hline GERT anger & PCL-R factor 2 & 11.469 & 0.011 & 0.003 & 3.387 & $<0.01$ \\
\hline \multirow{3}{*}{ GERT sadness } & Corrected model & 7.627 & & & & $<0.01$ \\
\hline & Sad $40 \%$ & 3.258 & 0.008 & 0.005 & 1.805 & $<0.10$ \\
\hline & PCL-R factor 2 & 9.653 & 0.009 & 0.003 & 3.107 & $<0.01$ \\
\hline GERT happy & PCL-R factor 2 & 11.469 & 0.011 & 0.003 & 3.387 & $<0.01$ \\
\hline GERT surprised & PCL-R factor 2 & 11.469 & 0.011 & 0.003 & 3.387 & $<0.01$ \\
\hline GERT disgusted & PCL-R factor 2 & 11.469 & 0.011 & 0.003 & 3.387 & $<0.01$ \\
\hline & Aggression against & & & & & \\
\hline GERT anger & Corrected Model & 4.936 & & & & $<0.01$ \\
\hline & Angry $70 \%$ & 3.220 & -0.008 & 0.004 & -1.794 & $<0.10$ \\
\hline & Angry $40 \%$ & 8.511 & 0.010 & 0.004 & 2.917 & $<0.01$ \\
\hline Affective Go/NoGo & Verbal Aggression & & & & & \\
\hline & Time & 5.133 & -0.013 & 0.006 & -2.266 & $<0.05$ \\
\hline & Physical Aggression & & & & & \\
\hline Affective Go/NoGo & Corrected model & 5.208 & & & & $<0.001$ \\
\hline & $d^{\prime}$ PosNeu & 3.775 & 0.013 & 0.007 & 1.943 & $<0.10$ \\
\hline & $d^{\prime}$ NeuNeg & 9.590 & -0.015 & 0.005 & -3.097 & $<0.01$ \\
\hline & PCL-R factor 1 & 4.589 & -0.006 & 0.003 & -2.142 & $<0.05$ \\
\hline & PCL-R factor 2 & 8.721 & 0.009 & 0.003 & 2.953 & $<0.01$ \\
\hline
\end{tabular}

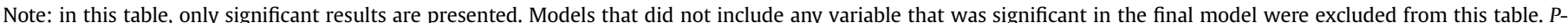
values of $<0.10$ were also displayed as the $\alpha$-criterion to eliminate variables was 0.10 . These effects are, however, not interpreted in the paper as significant results. 
the time factor was found: a longer time between the Affective Go/ NoGo and measurement of the violent incidents predicted fewer incidents. Less sensitivity to correctly react to neutral go-trails versus negative no-go trials predicted higher severity of physical aggression, in addition to the predictive value of the PCL-R factor 2 score.

\section{Discussion}

This study indicated that cognitive processes are valuable predictors of aggressive in-clinic incidents. An attentional bias towards aggression and threat, difficulty to recognize emotional faces, and a decreased sensitivity to respond to neutral stimuli and inhibit responses to negative stimuli predicted the number and severity of aggressive incidents within one year after the cognitive task. A schematic figure of the results can be found in Fig. 1.

A higher attentional bias towards aggressive or threatening stimuli predicted more violent incidents and more severe verbal aggression, next to the predictive value of the PCL-R. This adds to current knowledge on the relation between an attentional bias towards aggression and aggressive behavior (e.g. Chan et al., 2010; Brugman et al., 2015). In this study, however, the predictive validity of an attentional bias is not specific for aggressive stimuli, but also for stimuli related to general threat. The finding that attentional bias towards aggression and threat predicted the number of violent incidents and the severity of verbal aggression might be because in this population verbal aggression was most severe when violent incidents occurred. Verbal aggression is often the most used type of aggression in psychiatric hospitals (e.g. Foster et al., 2007; Stone et al., 2011), possibly because of the controlled environment of a forensic setting. Patients might be inclined to abstain from more severe forms of aggression, but still 'release' their frustration in terms of verbal aggression.

Difficulty recognizing mild sad faces, subtle happy faces, and subtle angry faces predicted the number and severity of violent incidents. Difficulty recognizing sad faces by antisocial patients in comparison to controls was also shown by Dolan and Fullam (2004) and Marsh and Blair (2008). Theoretically, detecting distress in others would inhibit antisocial behavior (e.g. Blair, 2005) and increase pro-social behavior (Marsh et al., 2007), but the current study showed that deficits in this process lead to aggressive behavior. Difficulty recognizing mild sad faces (i.e. 70\% intensity) predicted more violent incidents and more severe verbal incidents, even when controlling for the number of errors on subtle (40\%) and obvious (100\%) sad faces and the PCL-R factor scores. Subtle sad faces seem difficult and obvious faces easy to recognize for most patients (creating floor and ceiling effects), while difficulty to recognize mild sad faces (70\%) is crucial for predicting aggressive incidents. It is noteworthy that the level of sad face intensity that showed to be discriminative in our study (70\%) is highly similar to the level that has been found to be the threshold for recognition in samples of healthy men (72\%; Coupland et al., 2004). Apparently, it is at the normative threshold level of sad face detection that the predictive power of sad face recognition is manifested.

More severe verbal aggression was also predicted by more errors on subtle happy faces, which cannot be explained by the Integrated Emotion System (IES) model (Blair, 2005). Deficits in recognition of happy faces is generally not seen in antisocial populations (e.g. Marsh and Blair, 2008; Bowen et al., 2014). Possibly, happy faces with $40 \%$ intensity elicited aggressive behavior in those patients interpreting these faces as more mocking or provoking.

More errors on subtle angry faces predicted more severe aggression against property, indicating that subtle anger cues do not inhibit aggression against property, while mild or strong cues of anger do. Although antisocial patients do not generally show deficits in recognition of obvious angry faces (e.g. Marsh and Blair, 2008), it remains unclear how they perform on subtle angry faces in comparison to healthy participants. According to the results of Coupland et al. (2004) on recognition of angry faces in healthy males, the majority of the participants in our study would have difficulty in recognizing subtle angry faces. As aggression against property was rare in this sample, these results may be due to relatively few patients with a high level of errors on angry faces and higher levels of aggression against property.

Sensitivity to detect a neutral stimulus among negative stimuli predicted physical aggression. Patients who are more distracted by negative stimuli and less able to discriminate between neutral and negative stimuli are at more risk to display physical aggression. Little is known from previous studies on this issue. Verona et al. (2012) measured frontal P3-activity with EEG, which is heightened when inhibitory control is carried out on Go/NoGo tasks and in

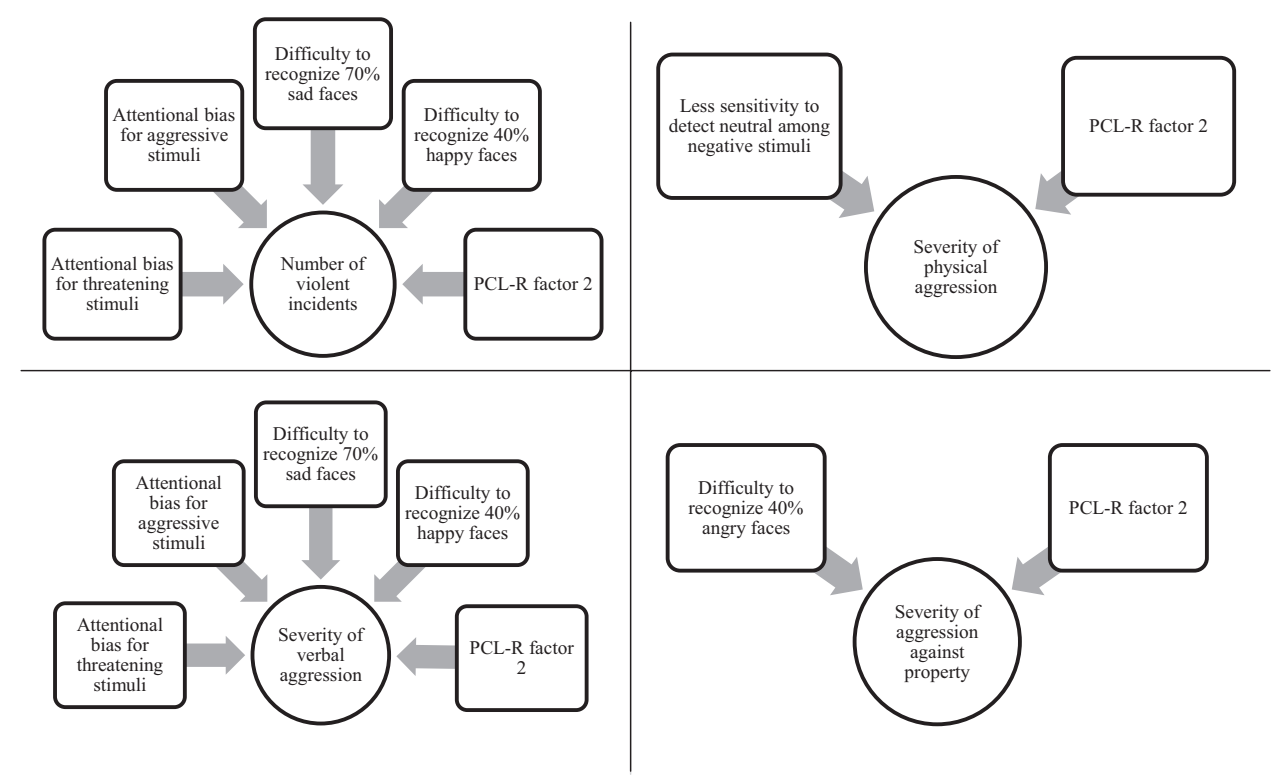

Fig. 1. Schematic Reproduction of Results. 
processing emotional information, in psychopathic offenders with antisocial offenders and controls. Antisocial offenders failed to refrain from emotional processing of negative stimuli on No/Go trials. Furthermore, enhanced processing of negative stimuli was related to more verbal and physical aggression, similar to the results in our study.

The number of aggressive incidents and severity of verbal and physical aggressive behavior was also predicted by the PCL-R factor 2. Kennealy et al. (2010) reported that PCL-R factor 2 was a stronger predictor of violent recidivism than factor 1 . Likewise, Coid et al. (2011) showed that violent reconvictions were correlated with 13 items of the PCL-R, which included all items of factor 2 of the PCL-R and only 3 of factor 1 . Although the PCL-R factor 2 is thus an important predictor of aggressive incidents, it should be noted that the cognitive factors measured in this study have predictive value in addition to the PCL-R factors included in the analyses.

Contrary, the result that a higher PCL-R factor 1 predicted less violent incidents in the model of the aggression-version of the Emotional Stroop could indicate a difference between primary and secondary psychopaths. While the secondary psychopath is the more 'hot-headed' variant showing more impulsive/reactive aggression, the primary psychopath more often shows premeditated or proactive violence (Skeem et al., 2007). The primary psychopath would more likely refrain from aggressive behavior when there is no benefit for him at that moment and only negative consequences. It is possible that the violent incidents we measured during a year consisted mostly of reactive/impulsive aggression.

No significant effects were found for the variables of the Signal Detection Task and the IAT. As patients reported that they found the Signal Detection Task to be quite difficult, a lack of significant effect could be due to a high number of random answers. As for the IAT, both words and pictures were used to categorize under the labels. Previous studies (e.g. Foroni and Bel-Bahar, 2010) showed that the magnitude of the IAT-effect is dependent on the stimuli-type, whereas IAT's using words as stimuli often show stronger IAT-effects than pictures, due to the fact that words and pictures differ on the level with which they represent the categories used (i.e. level of representation; Foroni and Bel-Bahar, 2010). Possibly, using only words would have yielded a stronger IAT-effect.

There was no significant reduction over time in the number of incidents or their severity for all models, except the model of the Affective Go/NoGo, in predicting the number or severity of violent incidents. One might expect that due to treatment, aggressive incidents would diminish over time. The overall time span between the cognitive measures and violent incidents might have been too short for treatment effects to become significant.

\subsection{Strengths and limitations}

This study was one of the first to test whether cognitive tasks predicted violent behavior of patients, extending the knowledge on these dynamic factors in aggressive behavior. Also, several cognitive tasks were tested on their predictive value of aggressive behavior in one study. Furthermore, using actual reports on violent in-clinic incidents strengthened the ecological validity of the results. A large time frame was used between the cognitive tasks and the violent incidents, making statements about the long-term predictive value of the cognitive tasks possible.

This study also has several limitations. First, only male offenders were included. While the sample is representative of the male-dominant offender population, the results may not be generalizable to female offenders. Second, the controlled environment of a forensic institution limits the number and severity of violent incidents, making it difficult to translate these results to an environment outside the clinic. It remains unclear whether the cognitive tasks maintain their predictive value outside the forensic clinics. Third, since the GERT and the Affective Go/NoGo provided multiple predictors (e.g. sad faces with $40 \%, 70 \%$, and $100 \%$ ), results on these tasks could be influenced by high inter-correlations among these variables. However, the alternative of including these variables into separate regression analyses would yield into too many regression analyses. Fourth, the problem of increased risk of type 2 errors due to multiple comparisons should be considered when interpreting the results. Thus, this study can be seen as hypothesis-generating.

\subsection{Clinical implications}

This study showed that the Emotional Stroop, GERT, and the Affective Go/NoGo predicted the amount and severity of violent incidents of forensic psychiatric patients. These results indicate that, after replication of these findings, cognitive tasks could have potential to complement current risk taxation instruments and facilitate and improve risk assessment in the future. Using cognitive tasks could give clinicians more insight in cognitive processes playing a role in aggressive behavior of forensic patients, which could then be targeted in treatment. Attentional bias modification (ABM), for example, potentially normalizes attentional bias. Most studies on ABM were conducted with anxiety patients (for a meta-analysis, see Mogoaşe et al., 2014), indicating that $A B M$ reduces anxiety symptoms. So far, the effect of ABM on aggressive behavior has not yet been studied, but could be promising. Also, trainings exist on improving recognition of emotional faces in different patient populations (e.g. Frommann et al., 2003), even in violent offenders (e.g. Schönenberg et al., 2014). More research on these types of interventions in forensic populations is needed to target cognitive biases and emotion recognition deficits.

\section{Acknowledgments}

This work was supported by a grant from the Netherlands Organization for Scientific Research (NWO;HCMI 10-19). We are grateful for the collaboration with the staff and patients of the forensic institute 'Pompekliniek' in Nijmegen, the Netherlands and 'Oldenkotte' in Rekken, the Netherlands.

\section{Appendix A. Supplementary material}

Supplementary data associated with this article can be found in the online version at http://dx.doi.org/10.1016/j.psychres.2016.01.035.

\section{References}

Banse, R., Messer, M., Fischer, I., 2015. Predicting aggressive behavior with the Aggressiveness-IAT. Aggress. Behav. 41, 65-83.

Bass, S.L.S., Nussbaum, D., 2010. Decision-making and aggression in forensic psychiatric inpatients. Crim. Justice Behav. 37 (4), 365-383.

Blair, R.J.R., 2005. Applying a cognitive neuroscience perspective to the disorder of psychopathy. Dev. Psychopathol. 17 (3), 865-891.

Bowen, K.L., Morgan, J.E., Moore, S.C., van Goozen, S.H.M., 2014. Young offenders' emotion recognition dysfunction across emotion intensities: explaining variation using psychopathic traits, conduct disorder and offense severity. J. Psychopathol. Behav. Assess. 36 (1), 60-73.

Brugman, S., Lobbestael, J., Arntz, A., Cima, M., Schuhmann, T., Dambacher, F., Sack, A.T., 2015. Identifying cognitive predictors of reactive and proactive aggression. Aggress. Behav. 41, 51-64.

Chan, O., Chow, K.K.-w, 2014. Assessment and determinants of aggression in a forensic psychiatric institution in Hong Kong, China. Psychiatry Res. 220 (1-2), 623-630. 
Chan, S.-C., Raine, A., Lee, T.M.C., 2010. Attentional bias towards negative affect stimuli and reactive aggression in male batterers. Psychiatry Res. 176 (2-3), 246-249.

Coid, J.W., Yang, M., Ullrich, S., Zhang, T., Sizmur, S., Farrington, D., Rogers, R., 2011 Most items in structured risk assessment instruments do not predict violence. J. Forensic Psychiatry Psychol. 22 (1), 3-21.

Coupland, N.J., Sustrik, R.A., Ting, P., Li, D., Hartfeil, M., Singh, A.J., Blair, R.J., 2004 Positive and negative affect differentially influence identification of facial emotions. Depression Anxiety 19 (1), 31-34.

Crick, N.R., Dodge, K.A., 1994. A review and reformulation of social informationprocessing mechanisms in children's social adjustment. Psychol. Bull. 115 (1), $74-101$.

Dambacher, F., Sack, A.T., Lobbestael, J., Arntz, A., Brugman, S., Schuhmann, T., 2014 Out of control Evidence for anterior insula involvement in motor impulsivity and reactive aggression. Soc. Cognit. Affect. Neurosci.

Dolan, M., Fullam, R., 2004. Theory of mind and mentalizing ability in antisocial personality disorders with and without psychopathy. Psychol. Med. 34 (6), 1093-1102.

Domes, G., Mense, J., Vohs, K., Habermeyer, E., 2013. Offenders with antisocial personality disorder show attentional bias for violence-related stimuli. Psychiatry Res. 209 (1), 78-84.

Eckhardt, C.I., Samper, R., Suhr, L., Holtzworth-Munroe, A., 2012. Implicit attitudes toward violence among male perpetrators of intimate partner violence: a preliminary investigation. J. Interpers. Violence 27 (3), 471-491.

Ekman, P., Friesen, W., 1976. Pictures of Facial Affect. Consulting Psychologists Press, Palo Alto.

Foroni, F., Bel-Bahar, T., 2010. Picture-IAT versus word-IAT: level of stimulus representation influences on the IAT. Eur. J. Soc. Psychol. 40, 321-337.

Foster, C., Bowers, L., Nijman, H., 2007. Aggressive behaviour on acute psychiatric wards: prevalence, severity and management. J. Adv. Nurs. 58 (2), 140-149.

Frommann, N., Streit, M., Wölwer, W., 2003. Remediation of facial affect recognition impairments in patients with schizophrenia: a new training program. Psychiatry Res. 117 (3), 281-284.

Gannon, T.A., Polaschek, D.L.L., 2006. Cognitive distortions in child molesters: a reexamination of key theories and research. Clin. Psychol. Rev. 26 (8), 1000-1019.

Grann, M., Långström, N., Tengström, A., Kullgren, G., 1999. Psychopathy (PCL-R) predicts violent recidivism among criminal offenders with personality disorders in Sweden. Law Hum. Behav. 23 (2), 205-217.

Hare, R.D., 2003. Manual for the Revised Psychopathy Checklist, 2nd ed. MultiHealth Systems, Toronto, ON, Canada.

Hare, R.D., Clark, D., Grann, M., Thornton, D., 2000. Psychopathy and the predictive validity of the PCL-R: an international perspective. Behav. Sci. Law 18 (5), 623-645.

Hildebrand, M., de Ruiter, C., de Vogel, V., van der Wolf, P., 2002. Reliability and factor structure of the Dutch language structure of Hare's Psychopathy Checklist-Revised. Int. J. Forensic Ment. Health 1 (2), 139-154.

Iria, C., Barbosa, F., Paixão, R., 2012. The identification of negative emotions through a go/no-go task: comparative research in criminal and non-criminal psychopaths. Eur. Psychol. 17 (4), 291-299.

Kennealy, P.J., Skeem, J.L., Walters, G.D., Camp, J., 2010. Do core interpersonal and affective traits of PCL-R psychopathy interact with antisocial behavior and disinhibition to predict violence? Psychol. Assess. 22 (3), 569-580.

Kobes, M.H.B.M., Nijman, H.H.L.I., Bulten, E.B.H., 2012. Assessing aggressive behavior in forensic psychiatric patients: validity and clinical utility of combining two instruments. Arch. Psychiatr. Nurs. 26 (6), 487-494.

Lang, P.J., Bradley, M.M., Cuthbert, B.N., 1997. International affective picture system (IAPS): Technical manual and affective ratings.

Lobbestael, J., Arntz, A., Cima, M., Chakhssi, F., 2009. Effects of induced anger in patients with antisocial personality disorder. Psychol. Med. 39 (4), 557-568.

MacMillan, N.A., Creelman, C.D., 1991. Detection Theory: A Users' Guide, 2nd ed. Lawrence Erlbaum Associates Publishers, Mahwah, NJ, US 2005.

Marsh, A.A., Blair, R.J.R., 2008. Deficits in facial affect recognition among antisocial populations: a meta-analysis. Neurosci. Biobehav. Rev. 32 (3), 454-465.
Marsh, A.A., Kozak, M.N., Ambady, N., 2007. Accurate identification of fear facial expressions predicts prosocial behavior. Emotion 7 (2), 239-251.

Mogoașe, C., David, D., Koster, E.H.W., 2014. Clinical efficacy of attentional bias modification procedures: an updated meta-analysis. J. Clin. Psychol. 70 (12), 1133-1157.

Nederlof, A.F., Muris, P., Hovens, J.E., 2011. Threat/control-override symptoms and emotional reactions to positive symptoms as correlates of aggressive behavior in psychotic patients. J. Nerv. Ment. Disord. 199 (5), 342-347.

Nijman, H., Geurkink, M., 2004. Agressie van gedetineerden met psychiatrische stoornissen.=Aggressive behaviour of prisoners with psychiatric disorders. Tijdschr. voor Psychiatr. 46 (9), 609-618.

Nosek, B.A., Banaji, M.R., 2001. The Go/NoGo association task. Soc. Cogn. 19 (6), 625-664.

Öhman, A., Lundqvist, D., Esteves, F., 2001. The face in the crowd revisited: a threat advantage with schematic stimuli. J. Pers. Soc Psychol. 80, 381-396.

Pham, T.H., Philippot, P., 2010. Decoding of facial expression of emotion in criminal psychopaths. J. Pers. Disord. 24 (4), 445-459.

Rebocho, M.F., Gonçalves, R.A., 2012. Sexual predators and prey: a comparative study of the hunting behavior of rapists and child molesters. J. Interpers. Violence 27 (14), 2770-2789.

Richetin, J., Richardson, D.S., Mason, G.D., 2010. Predictive validity of IAT aggressiveness in the context of provocation. Soc. Psychol. 41 (1), 27-34.

Ros, N., van der Helm, P., Wissink, I., Stams, G.J., Schaftenaar, P., 2013. Institutional climate and aggression in a secure psychiatric setting. J. Psychiatry Psychol. 24 (6), 713-727.

Schönenberg, M., Christian, S., Gaußer, A.K., Mayer, S.V., Hautzinger, M., Jusyte, A., 2014. Addressing perceptual insensitivity to facial affect in violent offenders: first evidence for the efficacy of a novel implicit training approach. Psychol. Med. 44 (5), 1043-1052.

Schönenberg, M., Jusyte, A., 2014. Investigation of the hostile attribution bias toward ambiguous facial cues in antisocial violent offenders. European Arch. Psychiatr. Clin. Neurosci. 264 (1), 61-69.

Skeem, J.L., Johansson, P., Andershed, H., Kerr, M., Louden, J.E., 2007. Two subtypes of psychopathic violent offenders that parallel primary and secondary variants. J. Abnorm. Psychol. 116 (2), 395-409.

Smith, P., Waterman, M., 2003. Processing bias for aggression words in forensic and nonforensic samples. Cogn. Emot. 17 (5), 681-701.

Snowden, R.J., Gray, N.S., Smith, J., Morris, M., MacCulloch, M.J., 2004. Implicit affective associations to violence in psychopathic murderers. J. Forensic Psychiatry Psychol. 15 (4), 620-641.

Sorgi, P., Ratey, J.J., Knoedler, D.W., Markert, R.J., Reichman, M., 1991. Rating aggression in the clinical setting: a retrospective adaptation of the Overt Aggression Scale: peliminary results. J. Neuropsychiatry Clin. Neurosci. 3 (2), S52-S56.

Stone, T., McMillan, M., Hazelton, M., Clayton, E.H., 2011. Wounding words: swearing and verbal aggression in an inpatient setting. Perspect. Psychiatr. Care 47 (4), 194-203.

Verhage, F., 1964. Intelligentie en leeftijd. Van Gorcum, Assen.

Verona, E., Sprague, J., Sadeh, N., 2012. Inhibitory control and negative emotional processing in psychopathy and antisocial personality disorder. J. Abnorm. Psychol. 121 (2), 498-510.

Wilson, C.M., Desmarais, S.L., Nicholls, T.L., Hart, S.D., Brink, J., 2013. Predictive validity of dynamic factors: assessing violence risk in forensic psychiatric inpatients. Law Hum. Behav. 37 (6), 377-388.

Wilson, K., Juodis, M., Porter, S., 2011. Fear and loathing in psychopaths: a metaanalytic investigation of the facial affect recognition deficit. Crim. Justice Behav. 38 (7), 659-668.

Zwets, A.J., Hornsveld, R.H.J., Muris, P., Huijding, J., Kanters, T., Snowden, R.J., van Marle, H., 2015. Implicit attitudes toward violence and their relation to psychopathy, aggression, and socially adaptive behaviors in forensic psychiatric inpatients. J. Forensic Psychiatry Psychol. 26 (5), 632-651. 